\title{
La adquisición de ebooks en una biblioteca universitaria puertorriqueña: condiciones de uso y preferencias de los usuarios
}

\author{
Marilyn Montalvo-Montalvo \\ Universidad de Puerto Rico, Recinto de Río Piedras, Sistema de Bibliotecas \\ marilyn.montalvo1@upr.edu \\ Jeannette LEBRÓN-RAMOS \\ Universidad de Puerto Rico, Recinto de Río Piedras, Biblioteca Escuela de Derecho \\ jeannette.lebrón2@upr.edu
}

Recibido: Agosto 2014

Aceptado: Octubre 2014

\begin{abstract}
Resumen: En este trabajo se tratan de determinar cuáles son las condiciones de uso más idóneas para la adquisición de ebooks en el Sistema de Bibliotecas de la Universidad de Puerto Rico, Recinto de Río Piedras (SB). El análisis se basa en las condiciones de uso establecidas por los proveedores de ebooks con los cuales el SB tiene acuerdos de suscripción o compra con acceso perpetuo. Además, se examinan las estadísticas de uso de algunas de las plataformas disponibles y los resultados de un sondeo realizado por el SB para conocer la opinión de la comunidad universitaria estudiantil sobre los ebooks.
\end{abstract}

Palabras clave: Bibliotecas Universitarias; Condiciones de Uso; Distribuidores; Libro Electrónico; Puerto Rico; Usuarios

Ebook acquisition in a puerto rican academic library: conditions of use and user's preferences

\begin{abstract}
The aim of this paper is to determine the acceptable conditions of use for the purchase of ebooks by the Library System of the University of Puerto Rico, Río Piedras (SB). The analysis is based on the conditions of use set by vendors of ebooks with which the SB has subscriptions or purchase with perpetual access agreements. Moreover, usage statistics of some of the available platforms and the results of a survey conducted by the SB in order to find out the views of the students about ebooks, are also discussed.
\end{abstract}

Keywords: Academic Libraries; Conditions of Use; Ebook; Puerto Rico; Users; Vendors

\section{INTRODUCCIÓN}

Es innegable que el avance de la digitalización, el desarrollo vertiginoso de la Internet y la potencia de Google, contribuyen a que los usuarios de las bibliotecas 
universitarias tengan mayores expectativas en cuanto a la disponibilidad de recursos informativos en formato electrónico. Muchos estudiantes no comprenden por qué los catálogos en línea incluyen, mayormente, información bibliográfica y se preguntan por qué las bibliotecas no tienen más libros digitales (ebooks) que puedan accederse en cualquier momento y desde cualquier lugar. Sin embargo, existe mucho desconocimiento sobre las condiciones de uso que los editores imponen al ebook y las particularidades de un mercado complejo e inestable en el que el libro y otros recursos informativos, nunca volverán a ser propiedad del que los adquiere.

\section{PROPÓSITO Y METODOLOGÍA}

El propósito de este trabajo es determinar cuáles son las condiciones de uso aceptables para la adquisición de ebooks en el Sistema de Bibliotecas de la Universidad de Puerto Rico, Recinto de Río Piedras (SB). El análisis se centrará, principalmente, en las condiciones de uso establecidas por los proveedores de ebooks con los cuales el SB tiene acuerdos de suscripción o compra con acceso perpetuo. Además, se examinarán las estadísticas de algunas de las plataformas disponibles y los resultados de un sondeo realizado por el SB para conocer la opinión de la comunidad universitaria estudiantil sobre los ebooks.

\section{ESTADO DE LA CUESTIÓN}

\subsection{DEL LIBRO TANGIBLE AL LIBRO VIRTUAL}

El libro impreso es tangible y definido. Cada ejemplar de un libro encuadernado en rústica o en tela es, a la vez, contenido y continente. Para leerlo, basta con pasar sus páginas. En cambio, el ebook precisa de un dispositivo intermediador computarizado para su lectura. El ebook resulta atractivo por su inmediatez y porque permite hacer búsquedas dentro del texto. La posibilidad de encontrar cualquier palabra o frase dentro de un texto representa un logro significativo con respecto a los libros impresos, que dependen de los índices analíticos y las concordancias. Por su naturaleza virtual, el ebook tiene el potencial de ser flexible, explorable y duplicable (Landow, 1996) pero esta volatilidad es también uno de problemas que enfrenta su mercado. La fatiga visual que causa la lectura secuencial y continuada en una pantalla retroiluminada (Alonso Arévalo y Cordón García, 2010; Morineau y otros, 2005; Romero, Iglesias y Giménez, 2013) es otra de sus limitaciones.

La virtualidad también tiene otras consecuencias. Un estudio, en el que participaron estudiantes de la National Central University de Taiwan, plantea las dificultades que presentan los ebooks para la construcción de mapas cognitivos efectivos, debido a la falta de las claves contextuales y los mecanismos de 
navegación necesarios para su desarrollo. Según los resultados del estudio, los ebooks no reproducen adecuadamente aquellas características del libro tangible que ayudan a recordar dónde se leyó la información y a traerla nuevamente a la memoria. Al parecer, aunque los textos digitales dispongan de hipervínculos para facilitar la navegación, dificultan la construcción de mapas cognitivos y causan desorientación en el lector ( $\mathrm{Li}$, Chen y Yang, 2013). Otro aspecto que puede incidir en la visualización del ebook es la distorsión de la identidad del texto monográfico que se puede producir en aquellas plataformas en las que no se muestra la obra completa, sino por capítulos.

No obstante, las bibliotecas han encontrado en los ebooks la solución de algunos de los problemas más acuciantes del libro impreso: los gastos de transporte, el robo, la morosidad en la devolución, la mutilación, el deterioro, las plagas y la falta de espacio. Además, el libro virtual tiene la capacidad potencial de permitir el uso simultáneo e ilimitado. Sin embargo, al adquirir ebooks las bibliotecas no compran un ejemplar físico de las obras, sino el derecho de acceder a ellas (Cordón García, Alonso Arévalo y Martín Rodero, 2010) con arreglo a las condiciones impuestas por los editores. Además, el acceso puede estar condicionado por los fallos tecnológicos, la demora en la renovación de las suscripciones y la falta de visibilidad. Tratándose de ejemplares virtuales, de los cuales las bibliotecas ya no son propietarias, no existen garantías de que puedan accederse en el futuro y su almacenamiento en repositorios locales o externos conlleva costos adicionales (Yelton, 2012). Uno de los factores que más incide en la comercialización de los ebooks es la protección de los derechos de autor. De ahí que existan varias modalidades de lectura y descarga. El modelo más estructurado es el que usa tecnologías de Digital Rights Management (DRM). Las plataformas con DRM requieren que los usuarios abran una cuenta, mediante la cual se regula la cantidad de veces que puede descargarse una porción predeterminada del ebook y su transferencia a un dispositivo de lectura por tiempo limitado, al cabo del cual desaparece. Uno de los efectos colaterales del DRM es que envía a los proveedores información sobre las preferencias de los usuarios, lo que podría constituir una invasión de la privacidad (Cohen, 2003; Hamaker, 2011). Teniendo en cuenta que las bibliotecas siempre han defendido la privacidad de la información relacionada con los recursos bibliográficos que los usuarios toman prestados, la adquisición de ebooks con DRM podría considerarse una claudicación de esta política. De hecho, algunas encuestas han mostrado que los jóvenes son conscientes de que los datos personales que se almacenan electrónicamente, especialmente en redes sociales, páginas web comerciales y páginas web de sus bibliotecas no están bien protegidos (De Rosa y otros, 2007).

La administración de los ebooks adquiridos por las bibliotecas demanda una atención constante, debido a que las condiciones de uso pueden variar, los contenidos pueden ser modificados o desaparecer inadvertidamente y las plataformas pueden presentar problemas de compatibilidad con los equipos de los 
usuarios. Además, la lectura y descarga de los ebooks requieren infraestructuras eficientes y rápidas. Por su naturaleza, el libro digital plantea, retos "de fragilidad física (problemas con el hardware), de fragilidad lógica (problemas con los formatos y sus posibles incompatibilidades) y fragilidad formativa (familiaridad con unas tecnologías en permanente renovación, con la exigencia de actualización permanente)" (Cordón García y otros, 2010, 73).

A pesar de que se debate si el ebook llegará a sustituir al libro impreso (Duguid, 1996; Eco, 1996), su mercado sigue siendo limitado, por diversas razones. Un factor determinante de esta situación es que las editoriales no suelen tener los derechos de la publicación digital ni de otros contenidos incluidos en una obra que no pertenecen al autor (Rich, 2009). Un estudio reciente llevado a cabo entre editoriales de diversos países revela que la mayoría de las editoriales han digitalizado menos del $25 \%$ de sus fondos impresos (Aptara, 2012). Por otra parte, la disponibilidad de la mayoría de los libros en formato digital suele estar sujeta a que la editorial haya obtenido la ganancia esperada en la venta de la versión original impresa, lo cual puede conllevar un retraso de varios años. Si bien la cantidad de ebooks ha aumentado mucho durante los últimos años, especialmente en Estados Unidos, la oferta sigue estando lejos de la demanda, ya que la creación de obra digital nativa sigue siendo menor que la impresa (Aptara, 2012; I.T. Strategies, 2013). Por otra parte, según un estudio realizado en la biblioteca del College of New Jersey, de los 6,960 libros que circularon entre 2008 y 2010, mayormente publicados después de 1990, solamente el 21\% estaba disponible en formato electrónico. Según estos resultados, los ebooks aún están en la etapa de suplementar a los libros impresos y el mercado del libro digital todavía es incierto e inestable. Por una parte, las editoriales deben considerar el timing de la publicación de sus libros en formato digital; por otra, los distribuidores deben esperar a que las editoriales les permitan comercializarlos (Link, Tosaka y Weng, 2012).

El panorama actual del mercado del libro digital español se refleja en varios informes y encuestas. En un estudio desarrollado en 2008 entre 342 editoriales españolas, el $57 \%$ de los encuestados consideraba que el libro impreso y el libro electrónico continuarían conviviendo. Tan sólo un $15 \%$ de los profesionales del sector opinaba que los ebooks llegarían a imponerse sobre los libros en papel y el $48 \%$ consideraba que los libros en papel seguirían siendo la principal vía de ingresos de las editoriales españolas en el 2020. Según el 44\% de los profesionales encuestados, el principal beneficiario de la digitalización del libro sería el lector, mientras que el $49 \%$ opinaba que las librerías serían las principales perjudicadas (Dosdoce y Ediciona, 2008). Una encuesta similar, llevada a cabo en 2009, reveló que el $57 \%$ de los participantes consideraba prioritario definir su modelo de negocio online (Dosdoce y Ediciona, 2009). En otra encuesta llevada a cabo en 2010 , en la que participaron 280 editoriales, si bien el $75 \%$ de los editores indicó que tenía proyectos de publicación en formato digital, también anticipaba que en 2013 la creación de obra exclusivamente en versión digital alcanzaría, como 
máximo, el $8 \%$ de su catálogo. No obstante, el $26 \%$ de los encuestados esperaba poder comercializar en 2012 más de la mitad de su catálogo en versión digital. También se preveía un aumento de los ebooks con DRM, ya que el $72 \%$ indicaba que, a partir de 2012, el formato preferido para comercializar la obra digitalizada sería el ePub (Federación de Gremios de Editores de España, 2011). Según datos más recientes, el formato PDF aún compite con el ePub (Ministerio de Educación, Cultura y Deporte, 2013) y los ebooks ya alcanzan en España $20 \%$ de la producción editorial, aunque su facturación aún no supera el 2.6\% de los ingresos totales del sector (Observatorio de la Lectura y el Libro, 2013).

El mercado de ebooks para las bibliotecas es muy complejo. Es evidente que a las editoriales les resulta más rentable vender o alquilar sus ebooks para uso individual que para uso colectivo. Muchas editoriales temen que la venta de ebooks a las bibliotecas en condiciones que permitan el uso ilimitado tenga un efecto negativo en su venta. Las políticas cambiantes de Macmillan, Simon and Schuster, Hachette, Penguin y Harper Collins son un claro ejemplo de las dificultades que enfrentan las bibliotecas a la hora de desarrollar colecciones de ebooks (Acedo y Leverkus, 2014; American Library Association, 2012; Enis, 2014; Zickuhr y otros, 2012). El Presidente de Ventas de Harper Collins ha sido explícito al manifestar que la editorial no puede seguir con el modelo de ventas a perpetuidad porque vulneraría seriamente sus ganancias (Marwell, 2011). Utilizando este argumento, hay editoriales que restringen la cantidad de veces al año que se puede acceder a los títulos adquiridos por las bibliotecas. El alegado riesgo que presenta para las editoriales la venta de ebooks a las bibliotecas también se está usando como argumento para prohibir el préstamo interbibliotecario (Litsey y Ketner, 2013). Algunos editores ya han propuesto que se sustituyan los préstamo por compras consorciada de los mismos títulos (McKiel, 2011), lo que provocaría una duplicidad innecesaria en los fondos de las bibliotecas y representaría un duro revés para este servicio. La oferta de ebooks en español es aún más escasa pero la cantidad de editoriales españolas que los ofrecen por medio de distribuidores, tales como Digitalia, Bibliotechnia, Gale Virtual Reference Library o eLibro, ha ido aumentando paulatinamente. No obstante, en su oferta hay duplicidad y se echan en falta las grandes editoriales españolas. Por otra parte, Libranda (2014), una empresa que distribuye contenidos digitales en todo el mundo y que tiene acuerdos con muchas editoriales españolas e hispanoamericanas, ha lanzado iBiblio, una plataforma para la gestión y préstamo de los ebooks en las bibliotecas, que opera con DRM (Observatorio de la Lectura y el Libro, 2012). Odilo, Xercode y Leer-e representan iniciativas similares. 


\subsection{OPINIÓN DE ESTUDIANTES Y BIBLIOTECARIOS SOBRE LOS EBOOKS}

Las ventajas potenciales que ofrece el libro en formato digital y la presión ejercida, tanto por el mercado, como por diferentes sectores de la sociedad afines al desarrollo tecnológico, le han dado un impulso a la adquisición de ebooks en las bibliotecas universitarias. Sin embargo, es importante conocer las preferencias de los usuarios. Según un estudio realizado en 2009 en el que participó una muestra del 3\% de los estudiantes de la Universidad de Illinois, alrededor del 57\% indicó que había usado ebooks alguna vez pero el $45 \%$ no sabía que la biblioteca disponía de ellos. En cuanto a la preferencia según formatos, el $25 \%$ de los estudiantes prefirió los libros impresos, el $12 \%$ los ebooks y la mayoría, (56\%) ambos formatos. Según los estudiantes, la disponibilidad inmediata (27\%), la posibilidad de hacer búsquedas dentro del texto (25\%) y el acceso desde cualquier lugar (17\%) eran las principales ventajas de los ebooks. Las principales desventajas atribuidas a los ebooks fueron las dificultades para leer en una pantalla (33\%), los problemas ocasionados por el DRM $(10 \%)$ y los problemas de naturaleza tecnológica (14\%) (Shelburne, 2009).

La opinión de los estudiantes universitarios ingleses acerca de los ebooks también ha sido recogida en un amplio estudio conducido en la Gran Bretaña durante los años 2008 y 2009 por el JISC. En el estudio se investigaron las percepciones de los estudiantes de 127 universidades sobre 36 libros de texto en formato electrónico, adquiridos por sus respectivas bibliotecas. Según las respuestas obtenidas, el $37 \%$ de los estudiantes encontró los libros a través del catálogo en línea y el $61 \%$ los localizó a través de enlaces en el portal de sus bibliotecas. En cuanto a la forma de lectura preferida, el $67 \%$ indicó que leía directamente los ebooks en formato digital, en lugar de tratar de imprimirlos, y el $54 \%$ consultó varios capítulos, a diferencia del $6 \%$ de los estudiantes que leyó el libro completo. Con respecto a las ventajas del ebook, 52\% de los estudiantes consideró que la mayor ventaja del ebook era el acceso en línea y el 13\% mencionó la posibilidad de buscar dentro del libro. Según los estudiantes, los ebooks deberían proveer uso ilimitado y simultáneo, mejor y más fácil acceso remoto, la posibilidad de descargarlos en sus equipos y la eliminación del DRM. Además, demostraron estar muy confundidos con la multiplicidad de rutas de acceso a los ebooks (catálogo en línea, páginas web de las bibliotecas, metabuscadores) y pidieron más divulgación y capacitación. Tampoco parecieron entender la distinción entre los recursos electrónicos provistos por sus instituciones y los que están disponibles en Internet, de forma gratuita. En cuanto a las preferencias entre el libro impreso y el electrónico, los estudiantes opinaron que preferían el ebook para extraer datos e imágenes. Por otra parte, indicaron que preferían el libro impreso para hacer lecturas más extensas, entre otras razones, 
porque estaban más familiarizados con este formato, les permitía una mayor concentración y lo consideraban más apropiado para hojearlo, tomar notas y marcar los textos (JISC, 2009).

Las encuestas llevadas a cabo anualmente por ECAR desde 2004 permiten conocer cómo las tecnologías de la información afectan la experiencia universitaria de los estudiantes subgraduados estadounidenses. Según la encuesta más reciente, la importancia otorgada a los ebooks por los estudiantes había aumentado de un $24 \%$ en 2010 a un $70 \%$ en 2012 . En cuanto a las competencias tecnológicas, los estudiantes indicaron que les convendría desarrollar aún más las destrezas necesarias para usar efectivamente los recursos electrónicos disponibles en sus respectivas universidades (Dahlstrom, 2012).

Un estudio llevado a cabo entre 1,375 estudiantes de Wesley College, auspiciado por la editorial Springer, reveló que el 39\% de los estudiantes prefería los libros impresos, aunque también usaba los ebooks, y solamente el 12\% prefería los ebooks. La mayoría de los estudiantes indicó que leía solamente una porción del ebook y si tenía que leer más de 10 páginas las imprimía. También fue mayoritaria la preferencia por la lectura directa en sus computadoras y la falta de interés en adquirir algún tipo de e-reader. Además, no se encontró relación entre poseer un e-reader y la cantidad de páginas leídas. Los estudiantes destacaron la importancia de que los ebooks permitan buscar dentro del texto, se puedan leer sin estar conectados a una red y puedan descargarse (Lenares, 2012).

Según la encuesta realizada por I.T. Strategies, en la que participaron 800 estadounidenses, consumidores de libros, que completaron la educación secundaria o estudios universitarios en 2013, entre las razones principales para comprar libros impresos se destacan las sensaciones positivas que el libro impreso provoca y la posibilidad de tenerlo en sus bibliotecas personales, así como la naturaleza tangible y legible del papel. Sin embargo, al analizar la proporción de ebooks y libros impresos que estos consumidores adquirieron en 2012, se descubre que la cantidad promedio de títulos adquiridos en ambos formatos fue similar (I.T. Strategies, 2013).

Entre los estudiantes universitarios parece haber bastante consenso en cuanto a las ventajas y desventajas de los ebooks. En cambio, las bibliotecas tienen ante sí el reto de seleccionar los mejores modelos de adquisición, desarrollar colecciones de ebooks que se ajusten a las expectativas de su clientela y continuar actualizando las colecciones impresas. Las opiniones vertidas por los bibliotecarios en diferentes encuestas muestran la complejidad del mundo digital.

En un estudio en el que se incluyeron seis bibliotecas de diversos países, las dos características más apreciadas por los bibliotecarios fueron las opciones de acceso y los ahorros en los costos de transportación y manejo (Renner, 2007). Por otra parte, los bibliotecarios que participaron en una encuesta internacional auspiciada por Ebrary que incluía, mayormente, bibliotecas universitarias de Estados Unidos, se inclinaron por el modelo de compra con acceso perpetuo para un usuario, con la opción de ampliarlo, según la demanda (McKiel, 2011). 
Según las opiniones de los bibliotecarios obtenidas en el estudio del JISC, los ebooks permiten solucionar problemas de robo y vandalismo, así como el préstamo de colecciones especiales o raras que, en formato impreso, tendría restricciones de uso. Los bibliotecarios también indicaron que los ebooks tenían el potencial de permitir el uso simultáneo y ofrecían opciones de búsqueda dentro del texto. Entre las desventajas señaladas, destacaron la complejidad de la adquisición de los ebooks en un mercado en el que la oferta y la demanda no coinciden, así como la gestión de diferentes licencias y modelos comerciales. Además, según los bibliotecarios, las condiciones de uso diferían de las preferencias de los usuarios y el costo de los libros de texto era muy alto. En cuanto a la divulgación de los ebooks, opinaron que conllevaba más esfuerzo, ya que su visibilidad exigía que estuvieran representados en el catálogo en línea, en el portal de la biblioteca, a través de sus respectivas plataformas $y$ en diversas herramientas de descubrimiento (JISC, 2009).

HighWire Press también ha explorado las diversas opiniones y prácticas existentes, relacionadas con la adquisición de ebooks en las bibliotecas. En una encuesta llevada a cabo entre 138 bibliotecarios de 13 países, pertenecientes, en su mayoría, a bibliotecas universitarias, el $83 \%$ de los participantes indicó que su modelo de adquisición preferido era el acceso perpetuo y la mayoría opinó que la facilidad de uso y la posibilidad de incluir los ebooks en el catálogo en línea eran los factores principales al escoger una plataforma de ebooks. Según los bibliotecarios, el PDF era el formato preferido por los usuarios y el $45 \%$ de los encuestados opinó que el DRM era el factor que más limitaba el uso del ebook. Además, los bibliotecarios señalaron como inaceptables las limitaciones a la reproducción de los textos y las restricciones a los préstamos interbibliotecarios (Newman, 2009).

Los estudios realizados por Library Journal entre los bibliotecarios de las bibliotecas académicas estadounidenses son muy reveladores. En el estudio de 2011 se observaba un aumento de las bibliotecas que estaban optando por el acceso perpetuo (78\%), aunque el número de suscripciones a colecciones de ebooks continuaba siendo alto (69\%). En 2010 el 73\% de los encuestados opinaba que el modelo ideal debería permitir acceso multiusuario y búsquedas ilimitadas, pero en 2011 el 65\% indicaba que su modelo de adquisición principal era el que permitía acceso a un usuario solamente. Este cambio de parecer, probablemente, guarda relación con la diferencia en el costo de ambos modelos. El estudio también reveló que las bibliotecas académicas invertían alrededor del $10 \%$ de su presupuesto en ebooks y los adquirían, mayormente, con el presupuesto de recursos electrónicos. Además, la mayoría de los títulos adquiridos eran obras de consulta o trabajos monográficos. Con respecto al acceso, el 85\% de los bibliotecarios encuestados en 2010 indicó que los ebooks se incluían en sus catálogos en línea (Library Journal, 2011). La encuesta realizada en 2012 reveló que la disponibilidad de ebooks se había mantenido en un 95\%. Durante este año, el porcentaje de bibliotecarios que indicó que la adquisición de ebooks no era su mayor prioridad, aumentó de un $54 \%$ a un $69 \%$ con respecto al año anterior. Según 
la percepción de la mayoría de los bibliotecarios, la demanda por este tipo de recursos había aumentado levemente. Aunque el $18 \%$ de los encuestados señaló que su biblioteca tenía más de 100,000 títulos, los datos de la encuesta no distinguen los ebooks suscritos en paquetes de aquellos adquiridos individualmente y con acceso a perpetuidad. Según los bibliotecarios, la mayoría de los usuarios leían los ebooks directamente en su plataforma, en sus propias computadoras y seguían prefiriendo el formato en PDF. En cuanto a los factores que limitaban el uso de los ebooks, en todos los informes de Library Journal se destacan los siguientes: el desconocimiento acerca de su disponibilidad, la preferencia por el libro impreso y las dificultades para leer en una pantalla. En el informe de 2012 surge como factor importante la limitación de la oferta (Library Journal, 2012). Las guías preparadas por IFLA (Johnson y otros, 2012) y ReadersFirst (2014) son claros ejemplos de los esfuerzos que se realizan para concienciar a los bibliotecarios sobre las implicaciones de la adquisición de ebooks.

Los estudios analizados muestran la complejidad del mundo digital, así como las expectativas que despierta. Los estudiantes coinciden en la conveniencia de los ebooks para acceder a ellos, hacer lecturas parciales y buscar dentro de los textos, pero siguen prefiriendo el libro impreso para hacer lecturas extensas. Además, señalan las dificultades de tener que buscarlos en diversos puntos de las páginas web de las bibliotecas y desean usarlos de forma ilimitada y simultánea. Por su parte, los bibliotecarios parecen desear lo mejor de dos mundos, en términos de acceso y costo, algo difícilmente compatible con los modelos de venta de los recursos bibliográficos intangibles (McKiel, 2011).

\section{LOS EBOOKS EN EL SISTEMA DE BIBLIOTECAS DE LA UPRRP}

\subsection{CONDICIONES DE USO}

El desarrollo de las colecciones de ebooks del SB se produce en el contexto de una universidad pública, cuyo presupuesto depende, en gran medida, de fondos gubernamentales. Además, se enmarca en un ambiente cultural y educativo desarrollado principalmente en castellano, a pesar de estar integrado políticamente a Estados Unidos, y en el servicio a una clientela universitaria cuyo perfil tecnológico apenas se conoce. Las 20 bibliotecas y colecciones del SB prestan servicios a una matrícula de aproximadamente 16,000 estudiantes Full Time Equivalent (FTE). El SB dispone de un acervo variado, mayormente impreso, pero desde 2002 ha estado suscribiendo o adquiriendo a perpetuidad diversas revistas, enciclopedias, diccionarios, libros, imágenes, tanto fijas como en movimiento, y otros documentos en formato electrónico. A todos estos recursos se les ha dado el nombre genérico de bases de datos. Así las conocen sus usuarios y así se promocionan. Los recursos informativos electrónicos se pagan con fondos de la partida de suscripciones, ya que no existe una asignación presupuestaria específica para estos formatos. 
El SB aún no ha adoptado una política sistemática de desarrollo de colecciones de ebooks, debido a la incertidumbre existente sobre las modalidades de adquisición disponibles, la falta de garantías de acceso a largo plazo y las diferentes condiciones de uso impuestas por editoriales y distribuidores. Como bien señala Soules (2008), ya no se trata únicamente de tramitar las recomendaciones de compra, hacer los pedidos y recibir los libros, sino de un proceso que conlleva un complejo entramado de decisiones que buscan atender necesidades, a menudo, conflictivas. Si hasta hace poco la función del SB había sido desarrollar y preservar acervos bibliográficos tangibles para sus usuarios presentes y futuros, ahora se enfrenta a un escenario cambiante de formatos intangibles que se entremezclan y desdibujan.

La adquisición de ebooks debe estar guiada, principalmente, por la calidad y pertinencia de los contenidos. En este aspecto, aunque todavía limitada, la oferta de ebooks de las editoriales supera la de los distribuidores, que están sujetos a que las editoriales les permitan su comercialización. Sin embargo, los intermediarios tienen la ventaja de que proveen contenidos de diversas editoriales en una sola plataforma. Por otra parte, también deben considerarse toda una serie de parámetros de adquisición, acceso y descarga establecidos por los proveedores de ebooks (Ver Tabla I), teniendo en cuenta que no todos los proveedores ofrecen las mismas condiciones de uso y que los parámetros tampoco son mutuamente excluyentes.

Tabla I. Parámetros de uso de los ebooks

Fuente: elaboración propia

\begin{tabular}{|c|c|c|}
\hline Adquisición & Acceso & Descarga \\
\hline $\begin{array}{l}\text { Suscripción anual / } \\
\text { Compra con acceso } \\
\text { perpetuo }\end{array}$ & $\begin{array}{l}\text { Acceso por IP Address / } \\
\text { Contraseña }\end{array}$ & $\begin{array}{l}\text { Opción para imprimir el } \\
\text { ebook completo o por partes }\end{array}$ \\
\hline $\begin{array}{l}\text { Tarifa de acceso anual / } \\
\text { Con o sin exención }\end{array}$ & $\begin{array}{l}\text { Cantidad de búsquedas limitadas } \\
\text { / Ilimitadas }\end{array}$ & $\begin{array}{l}\text { Opción para enviar por } \\
\text { correo electrónico el ebook } \\
\text { completo o por partes }\end{array}$ \\
\hline $\begin{array}{l}\text { Adquisición de títulos } \\
\text { individuales/Colecciones }\end{array}$ & $\begin{array}{l}\text { Acceso simultáneo a cada ebook } \\
\text { para un usuario / Varios usuarios } \\
\text { / Multiusuario }\end{array}$ & $\begin{array}{l}\text { Opción para descargar el } \\
\text { ebook completo o por partes }\end{array}$ \\
\hline $\begin{array}{l}\text { Divulgación de las } \\
\text { condiciones de uso }\end{array}$ & $\begin{array}{l}\text { Plataforma de búsqueda que } \\
\text { muestra los ebooks adquiridos / } \\
\text { Todo el catálogo }\end{array}$ & $\begin{array}{l}\text { DRM: control tecnológico de } \\
\text { las impresiones y descargas }\end{array}$ \\
\hline \multirow[t]{3}{*}{ Estadísticas de uso } & Registros MARC para descargar & $\begin{array}{l}\text { Autorización para tramitar } \\
\text { como préstamo } \\
\text { interbibliotecario el ebook } \\
\text { completo o por partes }\end{array}$ \\
\hline & $\begin{array}{l}\text { Configurable en herramientas de } \\
\text { descubrimiento }\end{array}$ & \\
\hline & $\begin{array}{l}\text { Intuitividad y estabilidad de la } \\
\text { plataforma }\end{array}$ & \\
\hline
\end{tabular}


El SB ha optado por iniciar el desarrollo de las colecciones de ebooks, tratando de darles prioridad a la calidad de las editoriales, la pertinencia curricular y los contenidos en español. También ha tratado de mantener un grupo reducido de plataformas diferentes, ya que la diversidad de condiciones de uso puede complicar mucho su administración y utilización. Hasta el momento, se han establecido acuerdos comerciales con las siguientes plataformas: Digitalia, Bibliotechnia, Gale Virtual Reference Library (GVRL), Springerlink, Ebrary, CRCNetbase y Safari. De las siete plataformas, Springerlink y CRCNetbase ofrecen sus propios ebooks y las restantes son distribuidoras. Con respecto a la diversidad temática, Digitalia, Bibliotechnia, GVRL, Springer y Ebrary ofrecen contenidos multidisciplinarios; Safari ofrece textos especializados en temas empresariales y tecnológicos que suelen formar parte del currículo universitario; GVRL ofrece obras de consulta; CRCNetbase ofrece colecciones orientadas hacia las ciencias naturales. Una de las mayores limitaciones encontradas es la escasez de ebooks en español. De momento, Digitalia, Bibliotechnia, Ebrary y GVRL ofrecen títulos en español, aunque puede haber duplicidad en sus catálogos. Estos proveedores no requieren que se firme una licencia de uso, lo que se convierte en un arma de doble filo, ya que elimina trámites legales que pueden tardar meses, pero deja al SB sin un documento formal que garantice las condiciones de uso ofrecidas por el vendedor de la empresa al momento de negociar la compra o suscripción de los ebooks. En el caso de los distribuidores, las condiciones de uso pueden ser más inestables, ya que están sujetas a los acuerdos negociados con las editoriales que representan. El análisis de las condiciones de adquisición, acceso y descarga vigentes revela las semejanzas y diferencias existentes entre los proveedores (Ver anexo 1).

Con respecto a los parámetros de Adquisición, el SB se ha ido decantando por el acceso perpetuo y la compra de títulos individuales. Los títulos adquiridos mediante la modalidad de acceso perpetuo se incorporan al catálogo en línea. Sin embargo, también se han estado suscribiendo varias colecciones temáticas de ebooks de CRCNetbase y Safari. Las suscripciones son polémicas, puesto que la renovación está sujeta a la asignación anual de fondos y a los vaivenes del mercado. Además, no existe garantía de que los mismos ebooks permanezcan en la plataforma. Sin embargo, sus colecciones ofrecen miles de títulos a los cuales se les incorporan anualmente nuevas publicaciones a un precio muy inferior del que tendría la compra de títulos individual con acceso perpetuo. Los libros de Safari tienen la particularidad de que los títulos suscritos se pueden cambiar por otros, periódicamente. En cuanto a las tarifas de acceso anuales que suelen conllevar las compras con acceso perpetuo, las colecciones temáticas de Springerlink, no requieren pagos adicionales. Los demás proveedores cobran una tarifa de acceso anual, de la cual las bibliotecas pueden estar exentas si adquieren más ebooks 
durante el año en curso o si, además de la compra de títulos individuales a perpetuidad, suscriben alguna colección. Aunque se prefiere la compra de títulos individuales, los ebooks de Springer, al momento de la compra, solamente estaban disponibles en colecciones temáticas, a precios muy económicos.

La divulgación de las condiciones de uso es uno de los parámetros más necesarios para promocionar los ebooks. Sin embargo, todos los proveedores adolecen de la falta de documentación completa. Ha sido necesario acudir a diversos documentos e incluso solicitar la información. Las respuestas enviadas y la información disponible en cada una de las plataformas deberían constituir documentos legales pero la carencia de licencias de uso en las que se establezcan detalladamente las cláusulas acordadas da pie a la ambigüedad y a que surjan cambios inesperados. En cuanto a la disponibilidad de informes estadísticos, todas las plataformas, excepto la de Digitalia, ofrecen estadísticas de uso que se ajustan al estándar Counter.

En lo que concierne a los parámetros de Acceso, todas las plataformas ofrecen acceso remoto por IP Address, búsquedas ilimitadas y registros MARC. Los registros de Bibliotechnia no han podido usarse, dado que no cumplen con los estándares de calidad del SB. Con respecto al acceso simultáneo, en los casos en que las condiciones establecidas requieren costos adicionales para ampliar la cantidad de accesos, el SB ha optado por adquirir una licencia solamente. Tal es el caso de Bibliotechnia y Ebrary. Los ebooks de Safari, cuya demanda se anticipaba, se han suscrito para dos usuarios simultáneos pero, después de formalizar la suscripción, se ha descubierto que el acceso es mucho más restringido, ya que la simultaneidad abarca, no a los títulos individuales, sino a toda la plataforma. Los demás proveedores ofrecen acceso simultáneo ilimitado. En cuanto a la opción de acceder solamente a los ebooks adquiridos o suscritos, todas las plataformas lo permiten, pero algunas son más transparentes que otras. Ebrary, GVRL y Bibliotechnia solamente muestran los ebooks adquiridos, CRCnetbase ofrece ambas opciones pero tiene seleccionados, por defecto, los títulos suscritos y Safari ofrece ambas opciones. Las plataformas que más dificultan el acceso a los títulos adquiridos son las de Springerlink, que tiene seleccionado, por defecto, todo su catálogo y Digitalia, que todavía no permite limitar las búsquedas a los títulos adquiridos, aunque lo tiene entre sus prioridades. La posibilidad de configurar los ebooks en plataformas de descubrimiento y el nivel de desarrollo de la plataforma también son factores que influyen en su acceso. De momento, todos los proveedores, excepto Bibliotechnia, han suscrito acuerdos con Worldcat Local, el metabuscador suscrito actualmente por el SB.

Las plataformas más intuitivas son las de GVRL y Ebrary porque llevan directamente al usuario a los ebooks adquiridos. Las demás presentan dificultades de diverso grado para encontrarlos. La mayoría de las plataformas son muy estables. Las que requieren mayor estabilidad, en términos de su navegabilidad y 
que han presentado problemas de acceso a algunos de sus títulos son las de Digitalia y Bibliotechnia.

En cuanto a los parámetros de Descarga, GVRL permite imprimir, enviar por correo electrónico y hacer descargas por capítulos directamente desde su plataforma. Los parámetros de descarga de los demás proveedores varían. Springerlink permite imprimir y descargar capítulos, CRCNetbase y Safari permiten imprimir capítulos. Digitalia permite imprimir diez páginas a la vez. Inicialmente, Bibliotechnia permitía imprimir los ebooks completos o por partes pero actualmente la mayoría de los textos no se pueden descargar ni imprimir. Las descargas y envíos por correo electrónico desde estas plataformas se pueden hacer, ya sea directamente o mediante la instalación de un programa de impresora virtual que permita almacenar los textos. Sólo las descargas de Ebrary están sujetas al DRM, lo que permite que los ebooks se pueden tomar prestados durante una semana, utilizando el software Adobe Digital Editions. Además, se pueden descargar en PDF, imprimir y enviar por correo electrónico segmentos que no excedan el $20 \%$ de la obra. Con respecto a la posibilidad de realizar préstamos interbibliotecarios, Bibliotechnia, GVRL, CRCNetbase y Safari lo prohíben expresamente. Los demás proveedores lo permiten con ciertas restricciones. La política más clara es la establecida por Springerlink; las demás están sujetas a interpretación.

\subsection{ESTADÍSTICAS DE USO}

El análisis de los informes de uso de los ebooks puede contribuir a una mayor comprensión de las preferencias de los usuarios (Bucknell, 2010; Lamothe, 2010). Uno de los informes estandarizados que permite medir el uso de los ebooks es el Counter Book Report 2 (R1) Number of Successful Section Requests by Month and Title. Aunque el informe tiene el propósito de medir las secciones consultadas, también ofrece datos sobre la cantidad de ebooks disponibles y su uso.

Analizamos el uso de los ebooks de Springer, CRCNetbase y GVRL durante los últimos tres años, ya que aún no hay suficientes datos para analizar las demás plataformas. Según hemos destacado, una de las dificultades que presenta la administración de los ebooks es la diversidad de modelos de adquisición. Los ebooks de Springer han sido adquiridos por colecciones y años específicos. Los libros de CRCNetbase se suscriben por colecciones, cuyo contenido varía anualmente. En cambio, los ebooks de GVRL se adquirieron individualmente. Hay que señalar que las estadísticas de Springer y CRCNetbase muestran los ebooks sin uso, pero no así las de GVRL. Tomando en consideración que no se puede comprobar si todos los ebooks de GVRL se utilizaron o si los informes no recogieron el dato, en este caso, hemos optado por examinar la cantidad de ebooks usados cinco veces o más. 
El análisis muestra que, aunque las colecciones de Springer contienen varios miles de títulos, la mayoría no se usó durante los años analizados. Igualmente, sólo entre el 11\% y 13\% de los más de 9,000 ebooks de CRCNetbase fueron utilizados alguna vez (Ver Tabla II y Figura 1).

Tabla II. Estadísticas de uso de los ebooks del Sistema de Bibliotecas Fuente: elaboración propia

\begin{tabular}{|c|c|c|c|c|}
\hline Proveedor & Año & Total ebooks & $\begin{array}{c}\text { Ebooks } \\
\text { usados }\end{array}$ & $\%$ \\
\hline \multirow{2}{*}{$\begin{array}{c}\text { Springer } \\
\text { (1 vez o más) }\end{array}$} & 2010 & 10173 & 285 & $3 \%$ \\
\cline { 2 - 5 } & 2011 & 11662 & 391 & $3 \%$ \\
\cline { 2 - 5 } & 2012 & 13043 & 575 & $4 \%$ \\
\hline \multirow{2}{*}{$\begin{array}{c}\text { CRCnetbase } \\
\text { (1 vez o más) }\end{array}$} & 2010 & 9034 & 980 & $11 \%$ \\
\cline { 2 - 5 } & 2011 & 9034 & 1136 & $13 \%$ \\
\cline { 2 - 5 } & 2012 & 9034 & 1032 & $11 \%$ \\
\hline \multirow{2}{*}{ (5VRL veces o más) } & 2010 & 145 & 89 & $61 \%$ \\
\cline { 2 - 5 } & 2011 & 130 & 93 & $72 \%$ \\
\cline { 2 - 5 } & 2012 & 278 & 187 & $67 \%$ \\
\hline
\end{tabular}

Figura 1. Estadísticas de uso de los ebooks: 2010-2012 Fuente: elaboración propia

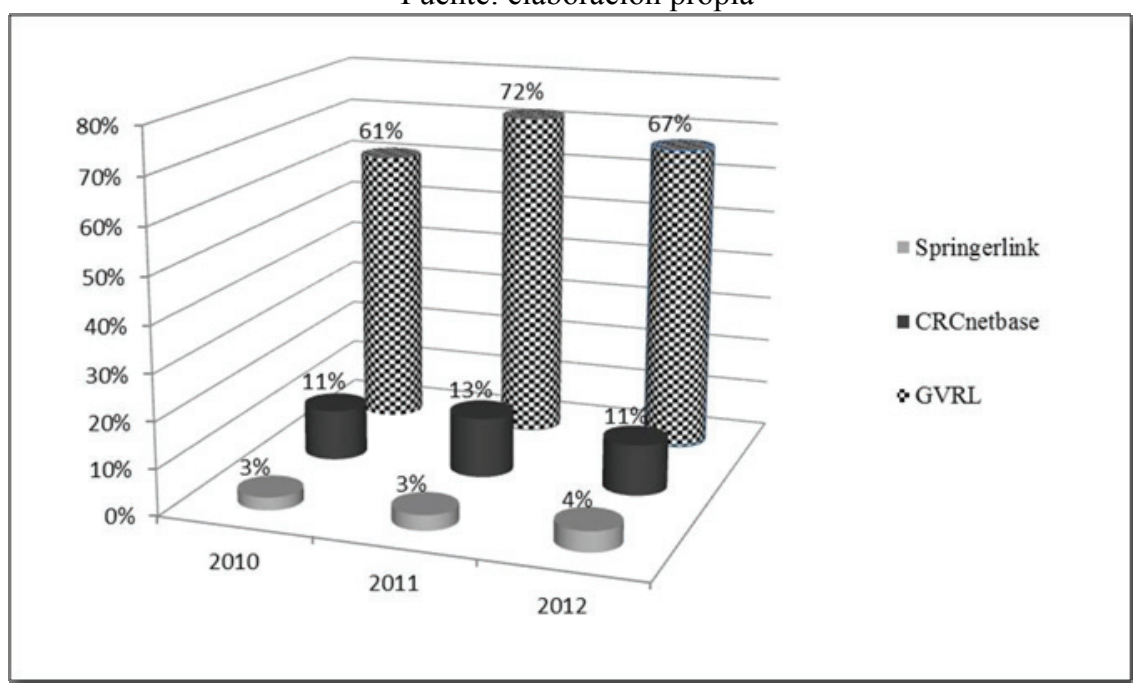

En cambio, más del $60 \%$ de los ebooks de GVRL fue utilizado cinco veces o más (Ver Tabla II y Figura 1). Este comportamiento podría guardar relación con varios factores. En primer lugar, a diferencia de los títulos de las colecciones de Springer y CRCNetbase, cada uno de los títulos de GVRL fue seleccionado por los bibliotecarios. En segundo lugar, a diferencia de las plataformas de Springer y CRCNetbase, que muestran todos sus contenidos, GVRL muestra solamente los ebooks adquiridos. Aunque las demás plataformas ofrecen opciones para limitar las 
búsquedas a los títulos suscritos o adquiridos, a muchos usuarios les resulta confuso y frustrante encontrarse con ebooks cuyos textos no pueden ver. En tercer lugar, solamente GVRL incluye ebooks en español. La disponibilidad en el catálogo en línea no parece tener un peso importante, ya que, tanto los ebooks de Springer como los de GVRL han sido catalogados. La divulgación de los ebooks es otro factor que seguramente incide en su utilización, pero desconocemos cuánto se han promocionado estas plataformas en las clases de capacitación que ofrece el SB.

\subsection{PREFERENCIAS DE LOS USUARIOS DEL SISTEMA DE BIBLIOTECAS}

El SB desarrolló una encuesta para conocer la opinión de los estudiantes del Recinto de Río Piedras sobre el uso de los ebooks y su disponibilidad en la página web del Sistema de Bibliotecas (Lebrón-Ramos y Montalvo-Montalvo, 2013). La encuesta se llevó a cabo con una muestra al azar de 373 estudiantes, correspondiente al 3\% de los estudiantes matriculados en las facultades y escuelas graduadas a las que el SB presta servicios. Los cuestionarios se distribuyeron entre los estudiantes que acuden a las bibliotecas y colecciones del SB, con el fin de lograr una mayor representatividad. Según los resultados obtenidos, el 73\% de los estudiantes había utilizado ebooks alguna vez pero el $43 \%$ no sabía que el SB disponía de estos recursos.

E1 99\% de los encuestados indicó que poseía algún equipo en el que podía leer los ebooks y, según la mayoría, los equipos que más usaban eran las Laptops $(60 \%)$ y los Smartphones (43\%). En cuanto a las descargas y el acceso, el $57 \%$ de los encuestados indicó que utilizaba los ebooks, tanto en la plataforma donde aparecen como descargándolos en sus equipos. El 73\% de los estudiantes que utilizaba los ebooks directamente donde aparecían señaló que solía buscar datos específicos $(40 \%)$ o leer algún capítulo (33\%), mientras que el $17 \%$ leía todo el libro. El $63 \%$ de los estudiantes indicó que prefería descargar todo el ebook, pero el $48 \%$ se conformaría con descargar el $20 \%$ de los textos de los ebooks adquiridos por el SB. La gran mayoría de los estudiantes (93\%) opinó que los ebooks del SB se deberían poder prestar. Además, el 60\% indicó que deberían poder accederse desde el catálogo en línea, las listas de bases de datos disponibles, los metabuscadores y Google. Con respecto a su impacto potencial, el 93\% de los estudiantes expresó que utilizaría más los servicios del SB si la oferta de ebooks fuera mayor. No obstante, casi todos (94\%) también opinaron que la biblioteca debería adquirir libros en ambos formatos.

En los comentarios vertidos al final de la encuesta, los estudiantes reafirmaron las respuestas ofrecidas, haciendo hincapié, tanto en la utilidad de los ebooks, como en su apego al libro impreso. Además, recomendaron que los ebooks se promocionaran más. Según los resultados de la encuesta, los estudiantes están preparados para usar libros en formato electrónico, necesitan que los ebooks 
adquiridos por el SB tengan una mayor visibilidad y prefieren los ebooks para hacer lecturas parciales. Además, desean tomarlos prestados y descargar porciones razonables de los textos. Por consiguiente, las expectativas de los estudiantes que acuden a las bibliotecas del SB son similares a las expresadas por estudiantes de otras latitudes.

\section{CONCLUSIONES}

El análisis de las condiciones de uso que caracterizan a un grupo variado de plataformas que suministran ebooks al SB, el examen de las estadísticas de uso de los ebooks adquiridos o suscritos por el SB desde hace varios años y, especialmente, las preferencias de los estudiantes que acuden las bibliotecas del $\mathrm{SB}$, ofrecen una idea de la complejidad que entraña la adquisición $\mathrm{y}$ administración de estos recursos electrónicos. Aunque los parámetros de uso examinados van perfilando las tendencias del mercado, es necesario que las bibliotecas traten de negociar las mejores condiciones.

En cuanto a la Adquisición de los ebooks, los parámetros más idóneos son los siguientes:

- La compra con acceso perpetuo, que ofrezca garantías de acceso prospectivas y que esté exenta de cargos adicionales al costo original.

- La adquisición de títulos individuales, que permita continuar con los procesos de selección necesarios para desarrollar colecciones pertinentes y balanceadas.

- La visibilidad de todos los términos de uso en los portales de las plataformas, que permita que los usuarios estén debidamente informados.

- La disponibilidad de informes estadísticos estandarizados, que arrojen luz sobre las preferencias de los usuarios.

Con respecto al Acceso, los parámetros más idóneos son los siguientes:

- Acceso por IP Address.

- Búsquedas ilimitadas.

- Acceso simultáneo multiusuario sin costo adicional.

- Plataformas que muestren solamente los ebooks adquiridos.

- Plataformas que dispongan de un nivel de desarrollo y estabilidad que propicie la confianza de los usuarios y minimice los cambios imprevistos.

- Plataformas que sean configurables en las herramientas de descubrimiento suscritas por el SB. 
- Disponibilidad de registros MARC que cumplan con estándares de calidad y requieran edición mínima.

En cuanto a la Descarga, los parámetros más idóneos son los siguientes:

- Mecanismos necesarios para facilitar las operaciones de impresión, envío y descarga del $20 \%$ de los ebooks, por lo menos. Sin lugar a dudas, la reproducción de los ebooks es uno de los aspectos más delicados del mercado digital, ya que podría constituir una violación de los derechos de autor. Sin embargo, teniendo en cuenta que dichos derechos están protegidos por las disposiciones relacionadas con el 'uso apropiado', establecidas en la Ley de Derechos de Autor de los Estados Unidos de 1976 (United States Copyright Office, 2011) que autoriza la reproducción de un número limitado de páginas, las bibliotecas deben exigir que se puedan hacer las descargas provistas por la ley.

- Autorización expresa para enviar porciones de un ebook, como parte de los servicios de préstamos interbibliotecarios.

Las tecnologías del DRM merecen otro tipo de consideración. El DRM permite hacer descargas controladas y préstamos virtuales, cumpliendo así con las expectativas mínimas de los usuarios del SB. No obstante, es muy preocupante que las bibliotecas, defensoras a ultranza de la privacidad de sus usuarios, estén adoptando plataformas que recogen información sobre los ebooks a los que acceden. Aunque pueda parecer que el uso de las tecnologías de la información es ya consustancial con la pérdida de la privacidad, es necesario advertirles a los usuarios que las plataformas que requieren la creación de una cuenta recogen información acerca de los ebooks que utilizan.

Las estadísticas de uso examinadas han mostrado la preferencia de los usuarios por GVRL, a pesar de la calidad indiscutible de las colecciones de Springer y CRCNetbase. Es posible que la disponibilidad de ebooks en español, la compra de títulos individuales, la visibilidad de los títulos adquiridos y la posibilidad de hacer impresiones, envíos y descargas por capítulos desde la plataforma hayan incidido en su mayor utilización. No obstante, será necesario analizar el uso prospectivo de todas las plataformas para determinar la validez de estas hipótesis.

Teniendo en cuenta las condiciones de uso establecidas por los proveedores con los cuales el SB mantiene acuerdos de suscripción o compra con acceso perpetuo, el uso real de los ebooks y las preferencias de los usuarios, el desarrollo de las colecciones de ebooks del SB debe continuar de manera cautelosa y selectiva, atenta a las mejores condiciones de uso. Aunque la cantidad de proveedores es aún manejable, la diversidad de plataformas no constituye un aliciente para los usuarios potenciales de los ebooks. Además, la falta de documentación que especifique con meridiana claridad el funcionamiento de cada una complica mucho la tarea de divulgación. Al SB le corresponde mantener la visibilidad de los ebooks, tanto en el catálogo en línea como en otros puntos de referencia y procurar que los usuarios 
comprendan que, a pesar de la flexibilidad potencial que ofrecen los recursos informativos intangibles, el uso del ebook tiene sus restricciones.

\section{REFERENCIAS BIBLIOGRÁFICAS}

ACEDO, Shannon y LEVERKUS, Cathy (2014). "Updates on ebooks: challenges \& changes", en Knowledge Quest, 43(1), 44-52.

ALONSO-ARÉVALO, Julio y José Antonio CORDÓN-GARCÍA (2010). "El libro electrónico ha llegado a las bibliotecas... y viene para quedarse", en $\mathrm{Mi}$ Biblioteca. (23), 74-83.

AMERICAN LIBRARY ASSOCIATION (2012). Ebook business models for public libraries [en línea]. Disponible en: http://connect.ala.org/files/80755/ EbookBusinessModelsPublicLibs.pdf [Consulta 20/09/2014].

APTARA (2012). Aptara's Fourth Annual eBook Survey of Publishers [en línea]. Disponible en:www.aptaracorp.com/sites/default/files/ebooks-survey-4revealing-business-ebooks-2009-2012.pdf [Consulta 20/09/2014].

BUCKNELL, Terry (2010). "The 'big deal' approach to acquiring e-books: a usage-based study", en Serials [en línea]. 23(2), 126-34. Disponible en: doi:10.1629/23126 [Consulta 20/09/2014].

COHEN, Julie E. (2003). "DRM and privacy", en Berkeley Technology Law Journal. 18, 575-617

CORDÓN-GARCÍA, José Antonio; Julio ALONSO-ARÉVALO y Helena MARTÍN RODERO (2010). "Los libros electrónicos: la tercera ola de la revolución digital", en Anales de Documentación, 13, 53-80.

DAHLSTROM, Eden (2012). ECAR study of undergraduate students and information technology [en línea]. Louisville, Colorado: EDUCAUSE Center for Applied Research, September Disponible en: https://net.educause.edu/ir/ library/pdf/ERS1208/ERS1208.pdf [Consulta 20/09/12].

DE ROSA, Cathy y otros (2007). Sharing, privacy and trust in our networked worl [en línea]. Dublin, Ohio: OCLC, Disponible en:www.oclc.org/content/dam/oclc/reports/pdfs/sharing.pdf [Consulta 31/01/14].

DOSDOCE y EDICIONA (2008). Digitalización del libro en España [en línea]. Madrid: Dosdoce; Barcelona, Ediciona. Disponible en: www.dosdoce.com/upload/ficheros/noticias/201005/0000000042.pdf [Consulta 19/01/13]

DOSDOCE y EDICIONA (2009). Digitalización del libro y uso de las redes sociales en el sector del libro [en línea]. Madrid: Dosdoce; Barcelona, Ediciona, Disponible en: www.aeapaf.org/wpcontent/uploads/2010/04/estudio_digitalizacion_en_espana_LIBER_2009.pdf [Consulta 19/09/2014]. 
DUGUID, Pau (1996)1. "Material matters: the past and futurology of the book". En: G. NUNBERG, ed. The future of the book. Turnhout: Brepols, pp. 63-101. ECO, Umberto (1996). "Afterword". En: G. NUNBERG, ed. The future of the book. Turnhout: Brepols, 1996, pp. 295-306.

ENIS, Matt (2014). "Technology: vendors talk ebook future”, en Library Journal. 139(14), 18.

FEDERACIÓN DE GREMIOS DE EDITORES DE ESPAÑA (2011). $2 d a$ encuesta sobre el libro digital en España: impacto de la digitalización en el catálogo, canales de distribución y de venta y política comercial [en línea]. Marzo Disponible en: www.mcu.es/libro/docs/MC/Observatorio/pdf/encuesta_libro_digital_2011.pdf [Consulta 15/10/13].

HAMAKER, Charles (2011). "Ebooks on fire”, en Searcher. 19 (10), 20-28.

I.T. STRATEGIES (2013). The evolution of the book industry: implications for U.S. book manufacturers and printers [en línea]. Boulder, Colorado: Ricoh, Disponible en:

http://rpp.ricoh-usa.com/images/uploads/Literature/whitepapers/IT-

Strategies_FINAL.pdf[Consulta 19/01/13].

JISC (2009). JISC national e-books observatory project: key findings and recommendations [en línea]. London: JISC Collections, November Disponible en: http://observatory.jiscebooks.org/reports/jisc-national-e-books-observatoryproject-key-findings-and-recommendations/ [Consulta 18/01/13].

JOHNSON, Sharon y otros (2012). Key Issues for E-Resource collection development: a guide for libraries [en línea]. The Hague: IFLA. Disponible en: http://www.ifla.org/files/assets/acquisition-collectiondevelopment/publications/electronic-resource-guide-en.pdf Consulta 19/09/2014].

LAMOTHE, Alain (2010). "Electronic book usage patterns as observed at an academic library: searches and viewings", en Partnership: the Canadian Journal of Library and Information Practices and Research. 5(1), 1-22.

LANDOW, George. P (1996). Twenty minutes into the future, or how are we moving beyond the book? En: G. NUNBERG, ed. The future of the book. Turnhout: Brepols, pp. 209-237.

LEBRÓN-RAMOS, Jeannette y Marilyn MONTALVO-MONTALVO (2013). Opinión de los estudiantes de la UPRRP sobre los ebooks Río Piedras: Sistema de Bibliotecas [en línea]. Disponible en: http://biblioteca.uprrp.edu/Encuesta\%20ebooks.pdf [Consulta 15/10/13]

LENARES, Deborah (2012). Springer ebooks: ebook use and acceptance in an undergraduate institution [en línea]. [N.Y.: Springer] Disponible en: http://static.springer.com/sgw/documents/1370809/application/pdf/H6593_CB_ WhitePaper_eBooks_Undergraduate+Inst.pdf [Consulta 17/01/13]. 
LIBRANDA (2014). Libranda \& bibliotecas [en línea]. Disponible en: http://www.libranda.com/default.aspx?id_seccion=4 [Consulta 17/7/14].

LIBRARY JOURNAL (2012). Ebook Usage in U.S. Academic Libraries. Second annual survey [en línea]. Disponible en: http://www.thedigitalshift.com/ research/ebook-usage-reports/academic/[Consulta 20/09/2014].

LIBRARY JOURNAL (2011). Ebook penetration \& use in U.S. academic libraries. New York: Library Journal.

LI, Lian-Yi, Gwo-Dong CHEN y Sheng-Jie YANG (2013). "Construction of cognitive maps to improve e-book reading and navigation", en Computers \& Education. 60(1), 32-39.

LINK, Forrest, Yuji TOSAKA y Cathy WENG (2012). "Notes on operation: employing usage data to plan for an e-book collection", en Library Resources \& Technical Services. 56(4), 254-265. ISSN 0024-2527.

LITSEY, Ryan y KETNER, Kenny (2013). Oh the possibilities: ebook lending and interlibrary loan, Interlending \& Document Supply, [en línea]. 41(4), 120-121. Disponible en: doi: http://dx.doi.org/10.1108/ILDS-09-2013-0027[Consulta 20/09/2014].

MARWELL, J. (2011). Open letter to librarians [en línea]. Disponible en: http://harperlibrary.typepad.com/my_weblog/2011/03/open-letter-tolibrarians.html [Consulta 18/01/13].

MCKIEL, Allen M (2011). Ebrary's download survey data [en línea]. Disponible en: http://www.ebrary.com/corp/collateral/en/Survey/2011_ebrary_download_ survey.pdf [Consulta 17/01/13].

MINISTERIO DE EDUCACIÓN, CULTURA Y DEPORTE (2013). Panorámica de la edición española de libros 2012 [en línea]. Madrid: Ministerio de Educación, Cultura y Deporte, Disponible en:

http://www.mcu.es/libro/docs/MC/Observatorio/pdf/PANORAMICA2012.pdf [Consulta 20/09/2014].

MORINEAU, Thierry [et al.] (2013). "The emergence of the contextual role of the e-book in cognitive processes through an ecological and functional analysis", en International Journal of Human-Computer Studies [en línea]. 62(3), 329348. Disponible en: doi: 10.1016/j.ijhcs.2004.10.002 [Consulta 18/01/13].

NEWMAN, Michael (2010). Highwire Press 2009 librarian ebook survey [en línea]. Palo Alto, California: Highwire Press. Disponible en: http:/highwire.stanford.edu/PR/HighWireEBookSurvey2010.pdf [Consulta 18/01/13].

OBSERVATORIO DE LA LECTURA Y EL LIBRO (2013). El sector del libro en España 2011-2013 [en línea]. Madrid: Ministerio de Educación, Cultura y DeporteDisponible en: www.mcu.es/libro/docs/MC/Observatorio/pdf/Sector_Libro_2011_13_sept13.p df, [Consulta 20/09/14]. 
OBSERVATORIO DE LA LECTURA Y EL LIBRO (2012). Situación actual y perspectivas del libro digital en España II: la producción española de libros digitales y su distribución y venta en la Red [en línea]. Madrid: Ministerio de Educación, Cultura y Deporte, Marzo. Disponible en: http://www.mcu.es/libro /docs/MC/Observatorio/pdf/situacion_librodigital_2.pdf[Consulta 18/01/13].

READERSFIRST (2014). Guide to Library E-Book Vendors: giving librarians the knowledge to be more effective e-book providers [en línea]. Disponible en: http://readersfirst.org/ReadersFirst-Guide--Library-E-Book-Vendors.pdf [Consulta 20/09/2014].

RENNER, Rita. A. (2007). Ebooks: costos y beneficios para bibliotecas académicas $y$ de investigación [en línea]. Disponible en: http://static.springer.com/sgw/documents/935238/application/pdf/Costos $+\mathrm{y}+\mathrm{Be}$ neficios+Para+Bibliotecas.pdf [Consulta 19/01/13].

RICH, Motoko (2009). "Legal battles rage over digital rights to older books: a digital world tests old publishing agreements", en International Herald Tribune. Paris, 14 de diciembre, p.16.

ROMERO OTERO, Irene Sofía; IGLESIAS FERNÁNDEZ, Esperanza; GIMÉNEZ TOLEDO, Elea (2013). "Uso, aceptación y expectativas del libro electrónico en una biblioteca de investigación", en BiD: textos universitaris de Biblioteconomia $i$ Documentació [en línea]. (31) Disponible en: http://bid.ub.edu/pdf/31/es/romero2.pdf [Consulta 19/09/2014].

SHELBURNE, Wendy Allen (2009). "E-book usage in academic library: user attitudes and behaviors", en Library Collections, Acquisitions and Technical Services [en línea]. 33(2-3), 59-72 ISSN 1464-9055. Disponible en: doi: 10.1016/j.lcats.2009.04.002 [Consulta 18/01/13].

SOULES, Aline (2008). "The shifting landscape of e-books", en New Library World [en línea]. 110(1-2), 7-21 ISSN 0307-4803. Disponible en: doi: 10.1108/03074800910928559[Consulta 18/01/13].

UNITED STATES COPYRIGHT OFFICE (2011). Copyright law of the United States and related laws contained in Title 17 of the United States Code [en línea]. Disponible en: http://www.copyright.gov/title17/circ92.pdf [Consulta 18/10/13].

YELTON, Andromeda (2012). "The Ethics of Ebooks", en Library Journal. 137(15), 30-31. ISSN 0363-0277.

ZICKUHR, Kathryn [et al] (2012). Libraries, patrons, and e-books [en línea]. Washington, D.C.: Pew Research Center's Internet \& American Life Project, June. Disponible en: http://libraries.pewinternet.org/2012/06/22/librariespatrons-and-e-books[Consulta 02/04/13]. 
Anexo 1. Condiciones de uso de los ebooks adquiridos en el Sistema de Bibliotecas.

Fuente: elaboración propia

\begin{tabular}{|c|c|c|c|c|c|c|c|}
\hline $\begin{array}{l}\text { Condiciones } \\
\text { de uso }\end{array}$ & Digitalia & Bibliotechnia & GVRL & Springerlink & Ebrary & CRC Netbase & Safari \\
\hline $\begin{array}{l}\text { Suscripción / Acceso } \\
\text { perpetuo }\end{array}$ & $\begin{array}{l}\text { Acceso } \\
\text { perpetuo }\end{array}$ & $\begin{array}{l}\text { Acceso } \\
\text { perpetuo }\end{array}$ & $\begin{array}{l}\text { Acceso } \\
\text { perpetuo }\end{array}$ & Acceso perpetuo & $\begin{array}{l}\text { Acceso } \\
\text { perpetuo }\end{array}$ & Suscripción & Suscripción \\
\hline $\begin{array}{l}\text { Costo anual por } \\
\text { acceso a los ebooks } \\
\text { adquiridos con } \\
\text { acceso perpetuo }\end{array}$ & Sí & $\mathrm{Si}$ & Sí & No & Sí & $\begin{array}{l}\text { No aplica } \\
\text { porque es } \\
\text { suscripción. }\end{array}$ & $\begin{array}{l}\text { No aplica } \\
\text { porque es } \\
\text { suscripción }\end{array}$ \\
\hline $\begin{array}{l}\text { Posibilidad de } \\
\text { exención de la tarifa } \\
\text { de acceso, } \\
\text { dependiendo de } \\
\text { cantidad de ebooks } \\
\text { adquiridos } \\
\text { anualmente con } \\
\text { acceso perpetuo }\end{array}$ & $\begin{array}{l}\text { Sí, si hay } \\
\text { consumo } \\
\text { subsecuente } \\
\text { durante el } \\
\text { año. }\end{array}$ & $\begin{array}{l}\mathrm{Si} \text {, si hay } \\
\text { consumo } \\
\text { subsecuente } \\
\text { durante el año. }\end{array}$ & $\begin{array}{l}\text { Se puede } \\
\text { negociar. }\end{array}$ & No aplica. & $\begin{array}{l}\text { Sí, si se } \\
\text { suscribe } \\
\text { alguna de sus } \\
\text { colecciones. }\end{array}$ & No aplica. & No aplica. \\
\hline $\begin{array}{l}\text { Adquisición de } \\
\text { títulos individuales / } \\
\text { Colecciones }\end{array}$ & Individuales & Individuales & Individuales & Colecciones & Individuales & Colecciones & Individuales \\
\hline $\begin{array}{l}\text { Divulgación de las } \\
\text { condiciones de uso }\end{array}$ & $\begin{array}{l}\text { Ha sido } \\
\text { necesario } \\
\text { requerir la } \\
\text { mayoría de la } \\
\text { información. }\end{array}$ & $\begin{array}{l}\text { Ha sido } \\
\text { necesario } \\
\text { requerir la } \\
\text { mayoría de la } \\
\text { información y } \\
\text { algunos de los } \\
\text { datos ofrecidos } \\
\text { son ambiguos. }\end{array}$ & $\begin{array}{l}\text { Ha sido } \\
\text { necesario } \\
\text { obtener la } \\
\text { información de } \\
\text { diferentes } \\
\text { fuentes. }\end{array}$ & $\begin{array}{l}\text { Ha sido } \\
\text { necesario } \\
\text { obtener la } \\
\text { información de } \\
\text { diferentes } \\
\text { fuentes. }\end{array}$ & $\begin{array}{l}\text { Ha sido } \\
\text { necesario } \\
\text { obtener la } \\
\text { información } \\
\text { de diferentes } \\
\text { fuentes. }\end{array}$ & $\begin{array}{l}\text { Ha sido } \\
\text { necesario } \\
\text { obtener la } \\
\text { información de } \\
\text { diferentes } \\
\text { fuentes. }\end{array}$ & $\begin{array}{l}\text { Ha sido } \\
\text { necesario } \\
\text { obtener la } \\
\text { información } \\
\text { de diferentes } \\
\text { fuentes. }\end{array}$ \\
\hline Estadísticas de uso & $\begin{array}{l}\text { Sí. Se pueden } \\
\text { descargar. }\end{array}$ & $\begin{array}{l}\text { Sí. Se pueden } \\
\text { descargar. }\end{array}$ & $\begin{array}{l}\text { Sí. Se pueden } \\
\text { descargar. }\end{array}$ & $\begin{array}{l}\text { Sí. Se pueden } \\
\text { descargar. }\end{array}$ & $\begin{array}{l}\text { Sí. Se } \\
\text { pueden } \\
\text { descargar. }\end{array}$ & $\begin{array}{l}\text { Sí. Se pueden } \\
\text { descargar. }\end{array}$ & $\begin{array}{l}\text { Sí. Se } \\
\text { pueden } \\
\text { descargar. }\end{array}$ \\
\hline $\begin{array}{l}\text { Acceso por IP } \\
\text { Address /Contraseña }\end{array}$ & IP & IP & IP & IP & IP & IP & IP \\
\hline $\begin{array}{l}\text { Cantidad de } \\
\text { búsquedas limitadas } \\
\text { / Ilimitadas }\end{array}$ & Ilimitadas & Ilimitadas & Ilimitadas & Ilimitadas & Ilimitadas & Ilimitadas & Ilimitadas \\
\hline $\begin{array}{l}\text { Acceso simultáneo a } \\
\text { cada ebook para un } \\
\text { usuario / Varios } \\
\text { usuarios / } \\
\text { Multiusuario }\end{array}$ & Multiusuario & Un usuario & Multiusuario & Multiusuario & Un usuario & Multiusuario & $\begin{array}{l}3 \text { usuarios } \\
\text { simultáneos } \\
\text { (NOTA: Este } \\
\text { proveedor } \\
\text { limita el } \\
\text { acceso a toda } \\
\text { la plataforma) }\end{array}$ \\
\hline $\begin{array}{l}\text { Plataforma de } \\
\text { búsqueda que } \\
\text { muestre solamente } \\
\text { los ebooks } \\
\text { adquiridos u ofrezca } \\
\text { la opción de } \\
\text { delimitar las } \\
\text { búsquedas a los } \\
\text { ítems adquiridos }\end{array}$ & $\begin{array}{l}\text { Se pueden ver } \\
\text { las portadas } \\
\text { de los ebooks } \\
\text { adquiridos en } \\
\text { una sección } \\
\text { aparte, pero } \\
\text { las búsquedas } \\
\text { remiten a todo } \\
\text { el catálogo de } \\
\text { libros y } \\
\text { revistas. }\end{array}$ & $\begin{array}{l}\text { Sí. Solamente } \\
\text { muestra los } \\
\text { ebooks } \\
\text { adquiridos. }\end{array}$ & $\begin{array}{l}\text { Sí. Solamente } \\
\text { muestra los } \\
\text { ebooks } \\
\text { adquiridos. }\end{array}$ & $\begin{array}{l}\text { Para ver los } \\
\text { contenidos con } \\
\text { texto completo } \\
\text { hay que eliminar } \\
\text { la marca que } \\
\text { aparece por } \\
\text { defecto en la } \\
\text { Búsqueda } \\
\text { Avanzada y que } \\
\text { muestra todo el } \\
\text { catálogo de } \\
\text { libros y revistas. }\end{array}$ & $\begin{array}{l}\text { Sí. Solamente } \\
\text { muestra los } \\
\text { ebooks } \\
\text { adquiridos. }\end{array}$ & $\begin{array}{l}\text { Sí. Los } \\
\text { contenidos con } \\
\text { texto completo } \\
\text { están } \\
\text { seleccionados } \\
\text { por defecto } \\
\text { pero si se } \\
\text { elimina la } \\
\text { marca, muestra } \\
\text { todo el } \\
\text { catálogo. }\end{array}$ & $\begin{array}{l}\text { Sí. Provee } \\
\text { una sección } \\
\text { para ver los } \\
\text { títulos } \\
\text { suscritos y } \\
\text { otra para ver } \\
\text { todo el } \\
\text { catálogo. }\end{array}$ \\
\hline $\begin{array}{l}\text { Registros MARC } \\
\text { para descargar }\end{array}$ & $\mathrm{Si}$ & Sí & Sí & Sí. & Sí & Sí & Sí \\
\hline $\begin{array}{l}\text { Configurable en } \\
\text { Worldcat Local }\end{array}$ & No & No & Sí & Sí & Sí & Sí & Sí \\
\hline
\end{tabular}




\begin{tabular}{|c|c|c|c|c|c|c|c|}
\hline $\begin{array}{l}\text { Intuitividad de la } \\
\text { plataforma }\end{array}$ & $\begin{array}{l}\text { No es } \\
\text { intuitiva. }\end{array}$ & $\begin{array}{l}\text { No es intuitiva } \\
\text { y las } \\
\text { condiciones de } \\
\text { uso se han } \\
\text { restringido sin } \\
\text { avisar. }\end{array}$ & $\begin{array}{l}\text { Es muy } \\
\text { intuitiva. }\end{array}$ & $\begin{array}{l}\text { Es poco } \\
\text { intuitiva. }\end{array}$ & $\begin{array}{l}\text { Es poco } \\
\text { intuitiva. }\end{array}$ & $\begin{array}{l}\text { Es muy } \\
\text { intuitiva. }\end{array}$ & $\begin{array}{l}\text { Es poco } \\
\text { intuitiva. }\end{array}$ \\
\hline $\begin{array}{l}\text { Estabilidad de la } \\
\text { plataforma }\end{array}$ & $\begin{array}{l}\text { Ha sido } \\
\text { necesario } \\
\text { notificar } \\
\text { problemas de } \\
\text { acceso a } \\
\text { títulos } \\
\text { adquiridos. } \\
\end{array}$ & $\begin{array}{l}\text { Ha sido } \\
\text { necesario } \\
\text { notificar } \\
\text { problemas de } \\
\text { acceso a títulos } \\
\text { adquiridos. }\end{array}$ & $\begin{array}{l}\text { El acceso a los } \\
\text { ebooks } \\
\text { adquiridos es } \\
\text { muy estable. }\end{array}$ & $\begin{array}{l}\text { El acceso a los } \\
\text { ebooks } \\
\text { adquiridos es } \\
\text { muy estable. }\end{array}$ & $\begin{array}{l}\text { El acceso a } \\
\text { los ebooks } \\
\text { adquiridos es } \\
\text { muy estable. }\end{array}$ & $\begin{array}{l}\text { El acceso a los } \\
\text { ebooks } \\
\text { adquiridos es } \\
\text { muy estable. }\end{array}$ & $\begin{array}{l}\text { El acceso a } \\
\text { los ebooks } \\
\text { adquiridos es } \\
\text { muy estable. }\end{array}$ \\
\hline $\begin{array}{l}\text { Opción para } \\
\text { imprimir el ebook } \\
\text { completo o por } \\
\text { partes }\end{array}$ & $\begin{array}{l}\text { Se pueden } \\
\text { imprimir } \\
\text { secciones } \\
\text { hasta un } \\
\text { máximo de } 10 \\
\text { páginas. }\end{array}$ & $\begin{array}{l}\text { La mayoría de } \\
\text { los ebooks no } \\
\text { se pueden } \\
\text { imprimir. }\end{array}$ & $\begin{array}{l}\text { Se puede } \\
\text { imprimir por } \\
\text { capítulos. }\end{array}$ & $\begin{array}{l}\text { Se puede } \\
\text { imprimir por } \\
\text { capítulos. }\end{array}$ & $\begin{array}{l}\text { Se puede } \\
\text { imprimir } \\
\text { hasta un } 20 \% \\
\text { del texto por } \\
\text { usuario. } \\
\text { El usuario } \\
\text { tiene que } \\
\text { crear una } \\
\text { cuenta. }\end{array}$ & $\begin{array}{l}\text { Se puede } \\
\text { imprimir por } \\
\text { capítulos. }\end{array}$ & $\begin{array}{l}\text { Se puede } \\
\text { imprimir por } \\
\text { secciones o } \\
\text { capítulos. }\end{array}$ \\
\hline $\begin{array}{l}\text { Opción para enviar } \\
\text { por correo } \\
\text { electrónico el ebook } \\
\text { completo o por } \\
\text { partes }\end{array}$ & $\begin{array}{l}\text { No incluye la } \\
\text { opción pero se } \\
\text { puede enviar } \\
\text { la misma } \\
\text { cantidad que } \\
\text { se puede } \\
\text { imprimir, si se } \\
\text { almacena en } \\
\text { una impresora } \\
\text { virtual (Ej.: } \\
\text { Cute PDF). }\end{array}$ & $\begin{array}{l}\text { No incluye la } \\
\text { opción pero se } \\
\text { puede enviar la } \\
\text { misma cantidad } \\
\text { que se puede } \\
\text { imprimir, si se } \\
\text { almacena en } \\
\text { una impresora } \\
\text { virtual (Ej.: } \\
\text { Cute PDF). }\end{array}$ & $\begin{array}{l}\text { Se puede } \\
\text { enviar por } \\
\text { correo } \\
\text { electrónico la } \\
\text { misma porción } \\
\text { del texto que se } \\
\text { puede } \\
\text { imprimir. }\end{array}$ & $\begin{array}{l}\text { No incluye } \\
\text { opción pero se } \\
\text { puede enviar la } \\
\text { misma porción } \\
\text { del texto que se } \\
\text { puede descargar. }\end{array}$ & $\begin{array}{l}\text { No incluye } \\
\text { opción pero } \\
\text { se puede } \\
\text { enviar la } \\
\text { misma } \\
\text { porción del } \\
\text { texto que se } \\
\text { puede } \\
\text { imprimir si se } \\
\text { almacenan en } \\
\text { una } \\
\text { impresora } \\
\text { virtual (Ej.: } \\
\text { Cute PDF). }\end{array}$ & $\begin{array}{l}\text { Se puede } \\
\text { enviar enlace y } \\
\text { la misma } \\
\text { porción del } \\
\text { texto que se } \\
\text { puede imprimir } \\
\text { si se almacenan } \\
\text { en una } \\
\text { impresora } \\
\text { virtual (Ej.: } \\
\text { Cute PDF). }\end{array}$ & $\begin{array}{l}\text { Se puede } \\
\text { enviar enlace } \\
\text { y la misma } \\
\text { porción del } \\
\text { texto que se } \\
\text { puede } \\
\text { imprimir si se } \\
\text { almacenan en } \\
\text { una } \\
\text { impresora } \\
\text { virtual (Ej.: } \\
\text { Cute PDF). }\end{array}$ \\
\hline $\begin{array}{l}\text { Opción para } \\
\text { descargar el ebook } \\
\text { completo o por } \\
\text { partes }\end{array}$ & $\begin{array}{l}\text { No incluye la } \\
\text { opción pero se } \\
\text { puede } \\
\text { descargar la } \\
\text { misma } \\
\text { cantidad de } \\
\text { que se puede } \\
\text { imprimir, si se } \\
\text { almacena en } \\
\text { una impresora } \\
\text { virtual (Ej.: } \\
\text { Cute PDF). }\end{array}$ & $\begin{array}{l}\text { No incluye la } \\
\text { opción pero se } \\
\text { puede descargar } \\
\text { la misma } \\
\text { cantidad que se } \\
\text { puede imprimir, } \\
\text { si se almacena } \\
\text { en una } \\
\text { impresora } \\
\text { virtual (Ej.: } \\
\text { Cute PDF). }\end{array}$ & $\begin{array}{l}\text { Se puede } \\
\text { descargar la } \\
\text { misma porción } \\
\text { del texto que se } \\
\text { puede } \\
\text { imprimir. }\end{array}$ & $\begin{array}{l}\text { Se puede } \\
\text { descargar la } \\
\text { misma porción } \\
\text { del texto que se } \\
\text { puede imprimir. }\end{array}$ & $\begin{array}{l}\text { Se puede } \\
\text { descargar la } \\
\text { misma } \\
\text { porción del } \\
\text { texto que se } \\
\text { puede } \\
\text { imprimir y se } \\
\text { puede } \\
\text { descargar el } \\
\text { ebook por } 7 \\
\text { días con } \\
\text { Adobe } \\
\text { Digital } \\
\text { Editions. El } \\
\text { usuario tiene } \\
\text { que crear una } \\
\text { cuenta. }\end{array}$ & $\begin{array}{l}\text { Se puede } \\
\text { descargar por } \\
\text { capítulos. }\end{array}$ & $\begin{array}{l}\text { No incluye } \\
\text { opción pero } \\
\text { se puede } \\
\text { descargar la } \\
\text { misma } \\
\text { porción del } \\
\text { texto que se } \\
\text { puede } \\
\text { imprimir si se } \\
\text { almacenan en } \\
\text { una } \\
\text { impresora } \\
\text { virtual (Ej.: } \\
\text { Cute PDF). }\end{array}$ \\
\hline $\begin{array}{l}\text { DRM: control de las } \\
\text { impresiones y } \\
\text { descarga del libro } \\
\text { completo }\end{array}$ & No & No & No & No & Sí & No & No \\
\hline
\end{tabular}




\begin{tabular}{|c|c|c|c|c|c|c|c|}
\hline $\begin{array}{l}\text { Autorización para } \\
\text { tramitar como } \\
\text { préstamo } \\
\text { interbibliotecario el } \\
\text { libro completo o por } \\
\text { partes }\end{array}$ & $\begin{array}{l}\text { "Se pueden } \\
\text { prestar } \\
\text { páginas } \\
\text { impresas, o } \\
\text { fragmentos } \\
\text { del libro, pero } \\
\text { no enviar } \\
\text { archivos } \\
\text { enteros" (cita } \\
\text { textual). }\end{array}$ & $\begin{array}{l}\text { No está } \\
\text { autorizado. }\end{array}$ & $\begin{array}{l}\text { No. Está } \\
\text { expresamente } \\
\text { prohibido. }\end{array}$ & $\begin{array}{l}\text { Sí. Se puede } \\
\text { enviar a una } \\
\text { biblioteca, de } \\
\text { forma impresa o } \\
\text { electrónica, } \\
\text { partes } \\
\text { insubstanciales } \\
\text { de un ebook, } \\
\text { tales como un } \\
\text { capítulo, para } \\
\text { propósitos } \\
\text { educativos o de } \\
\text { investigación. Se } \\
\text { autoriza la } \\
\text { transmisión } \\
\text { electrónica } \\
\text { mediante } \\
\text { sistemas } \\
\text { seguros, tales } \\
\text { como Ariel o } \\
\text { Prospero. Los } \\
\text { archivos así } \\
\text { enviados tienen } \\
\text { que llevar un } \\
\text { aviso que haga } \\
\text { referencia a los } \\
\text { derechos de } \\
\text { autor. Las } \\
\text { solicitudes deben } \\
\text { cumplir con el } \\
\text { Copyright Law } \\
\text { (17 USC } § 108 \text { y y } \\
\text { la cláusula } 3 \text { de } \\
\text { los Guidelines } \\
\text { preparados por } \\
\text { la National } \\
\text { Commission on } \\
\text { New } \\
\text { Technological } \\
\text { Uses of } \\
\text { Copyrighted } \\
\text { Works. } \\
\end{array}$ & $\begin{array}{l}\text { Sí. Se pueden } \\
\text { tramitar } \\
\text { pociones de } \\
\text { un ebook, } \\
\text { según lo } \\
\text { previsto en el } \\
\text { Copyright } \\
\text { Law (17 USC } \\
\text { \$108). }\end{array}$ & $\begin{array}{l}\text { Está prohibida } \\
\text { la } \\
\text { redistribución } \\
\text { de los } \\
\text { contenidos. }\end{array}$ & $\begin{array}{l}\text { No está } \\
\text { autorizado. }\end{array}$ \\
\hline
\end{tabular}

